\title{
EXPERIÊNCIA ESTÉTICA NO CONTEXTO ESCOLAR PARA PESSOA COM SÍNDROME DE DOWN
}

\section{CELI CORRÊA NERES}

Docente do curso de Pedagogia e do Mestrado Profissional em Educação da Universidade Estadual de Mato Grosso do Sul. ORCID: 0000-0001-9864-2180. E-mail: celi@uems.br

\section{ANA PAULA NOGUEIRA}

Mestre em Educação Especial pela Universidade Estadual de Mato Grosso do Sul. Licenciada em Artes Visuais pela Faculdade de Artes, Letras e Comunicação da Universidade Federal de Mato Grosso do Sul - UEMS. ORCID: 0000-0002-1550-7037E-mail: lua_anarte@, hotmail.com 


\section{EXPERIÊNCIA ESTÉTICA NO CONTEXTO ESCOLAR PARA PESSOA COM SÍNDROME DE DOWN}

O presente artigo aborda resultados de uma pesquisa que buscou evidenciar as práticas realizadas nas aulas de arte, no contexto da educação especial, com vistas à construção de um olhar sensível, sob o ponto de vista da experiência estética, sobre as atividades artísticas desenvolvidas para pessoas com deficiência intelectual, aqui apresentado como um indivíduo com Síndrome de Down. O trabalho foca a experiência desenvolvida em sala de aula e apresenta como base teórica as pesquisas de L. S. Vigotski, em especial a apresentada na obra A Psicologia da Arte (1999). Neste artigo, a narrativa do desenvolvimento da atividade prática vem precedida de considerações a respeito da experiência estética no contexto escolar. Tais considerações são pertinentes para corroborar com entendimento dos efeitos da produção artística no desenvolvimento humano, tal como mencionado por Vigotski (1999). Para o autor, a produção artística interfere na organização psíquica do indivíduo, possibilitando a cada um a elevação da condição do ser simplista para o gênero humano universal. A análise da atividade revelou que os alunos com Síndrome de Down têm condições de se apropriarem dos elementos estéticos e transformá-los em aprendizado, desenvolvendo as suas funções psicológicas superiores.

Palavras-Chave: Síndrome de Down. Vivência Estética. Arte na Educação Especial.

\section{AESTHETIC EXPERIENCE IN THE SCHOOL CONTEXT FOR A PERSON WITH DOWN SYNDROME}

This article deals with the results of a research that sought to highlight the practices performed in art classes in the context of special education, with a view to constructing a sensitive view, from the point of view of the aesthetic experience, on the artistic activities developed for people with intellectual disability, presented here as an individual with Down Syndrome. The work focuses on the experience developed in the classroom and presents as a theoretical basis the research of L.S.Vigotski, especially the one presented in the work The Psychology of Art (1999). In this article, the narrative of the development of practical activity is preceded by considerations about aesthetic experience in the school context. Such considerations are pertinent to corroborate with understanding the effects of artistic production on human development, as mentioned by Vigotski (1999). For the author, the artistic production interferes in the psychic organization of the individual, enabling each one to elevate the condition of the simplistic being to the universal human race. The analysis of the activity revealed that students with Down Syndrome are able to appropriate the aesthetic elements and transform them into learning, developing their higher psychological functions.

Keywords: Down syndrome. Aesthetic Experience. Art in Special Education 


\section{EXPERIENCIA ESTÉTICA EN EL CONTEXTO ESCOLAR PARA PERSONA CON SÍNDROME DE DOWN}

El presente artículo aborda resultados de una investigación que buscó evidenciar las prácticas realizadas en las clases de arte, en el contexto de la educación especial, con miras a la construcción de una mirada sensible, desde el punto de vista de la experiencia estética, sobre las actividades artísticas desarrolladas para personas con discapacidad intelectual, aquí presentado como un individuo con Síndrome de Down. El trabajo enfoca la experiencia desarrollada en el aula y presenta como base teórica las investigaciones de L.S.Vigotski, en especial la presentada en la obra La Psicología del Arte (1999). En este artículo, la narrativa del desarrollo de la actividad práctica viene precedida de consideraciones acerca de la experiencia estética en el contexto escolar. Tales consideraciones son pertinentes para corroborar con entendimiento de los efectos de la producción artística en el desarrollo humano, según lo mencionado por Vigotski (1999). Para el autor, la producción artística interfiere en la organización psíquica del individuo, posibilitando a cada uno la elevación de la condición del ser simplista para el género humano universal. El análisis de la actividad reveló que los alumnos con Síndrome de Down tienen condiciones de apropiarse de los elementos estéticos y transformarlos en aprendizaje, desarrollando sus funciones psicológicas superiores.

Palabras clave: Síndrome de Down. Vivencia Estética. Arte en la Educación Especial. 


\section{EXPERIÊNCIA ESTÉTICA NO CONTEXTO ESCOLAR PARA PESSOA COM SÍNDROME DE DOWN}

\section{Introdução}

Das questões em que se ocupa a arte para pessoas com deficiência intelectual, evidenciar as experiências estéticas no contexto escolar é enfatizar o valor dos efeitos desta vivência e da produção artística do aluno com deficiência. Partindo deste pressuposto, a proposta pedagógica apresentada neste artigo coloca em prática o que Fernandes (2016) propõe a respeito do papel do professor em relação às aulas de arte na perspectiva da educação inclusiva. Para a autora, há uma necessidade de se elaborar, de forma criativa, diferentes atividades valorizando experiências artísticas e estéticas, respeitando as necessidades educacionais assim como o tempo de aprendizagem do aluno. A autora faz um destaque sobre a necessidade de o professor ter clareza sobre o seu papel profissional, seja na escola especial ou na comum, o que revela a preocupação em se evitar a reprodução de metodologias já superadas.

$\mathrm{Na}$ história recente, o ensino de arte passou por uma nova caracterização, na qual as práticas artísticas eram trabalhadas como uma forma de complemento pedagógico, sendo comum as práticas de colorir imagens feitas pelos adultos em folhas mimeografadas, como exercícios de coordenação motora para fixação e memorização de letras e números (MEC/SEF, 1998). Pesquisas produzidas no início do século XX, no campo da psicologia e da educação trouxeram princípios que reconheciam a arte da criança como manifestação espontânea e autoexpressiva: valorizavam a livre expressão e a sensibilização para o experimento artístico (MEC/SEF, 1998). No princípio foi uma importante evolução que, aos poucos, tornou-se o fazer pelo fazer.

A arte não está somente ligada à expressão de ideias e sentimentos, nem possui preocupação exclusiva com a emoção. O homem é um ser social e a arte é fenômeno que historicamente se modifica, fortalecendo a coletividade humana. Ademais, o ensino das artes tem se constituído como importante instrumento para o aprimoramento do conhecimento sensível do mundo (CASTILHO; NASCIMENTO; FERNANDES, 2008), por possuir conteúdos que estimulam o desenvolvimento do aluno.

Para Barroco e Superti (2014), a arte está em constante relação com a objetividade humana, o que permite o entendimento da potencialidade humana. Nesse sentido, a arte possui um papel importante, pois está diretamente ligada à vida e às relações sociais. Dialeticamente, essas relações 
sociais, por meio da apreensão da realidade e trabalhados a partir dela, oportunizam subsídios para elaboração do conteúdo e do estilo artístico. Ainda assim, a obra de arte não se configura a cópia fiel da realidade, mas gera algo novo, resultado da ação criativa, transformando-se em um produto cultural.

Considerando a dinâmica envolvida na natureza social da arte e a relação com a psicologia, torna-se claro como a experiência estética atua no desenvolvimento das funções psicológicas superiores e como elas são objetivadas. Vigotski (1999) esclarece alguns conceitos, como a formação do psiquismo humano, das generalizações e tomada de consciência. Conforme o autor, a generalização é uma forma de organização da consciência, que acontece a partir do que foi vivenciado em determinadas situações ou experiências. Essa consciência é considerada pelo autor como sendo a síntese das funções superiores.

A consciência é formada a partir da ação do homem sobre o mundo, e vice-versa, sob a mediação do signo em sua complexidade (considerando a capacidade analítica, de síntese e de generalização que a ação mediada pelo signo pode implicar). A consciência, assim, se manifesta e se forma contando com diferentes elaborações, sendo a arte uma delas (BARROCO; SUPERTI; 2014, p. 26).

Diante do entendimento sobre o caráter formador da arte e as relações da experiência estética no contexto escolar, seja do aluno com ou sem deficiência, a análise da proposta pedagógica que se segue retrata como estas questões se revelam na prática, permitindo, a demonstração da dinâmica existente no trabalho de arte realizado com alunos com Síndrome de Down, assim como as suas especificidades.

Por meio da análise das práticas e da avaliação que valoriza a subjetividade, tanto do processo quanto do aluno, legitimam-se as ações do professor de arte que precisa ter conhecimento da sua função, assim como ter claro para si alguns conceitos, no caso em pauta, a compreensão de experiência estética e sua vivência no contexto escolar. 


\section{A experiência estética no contexto escolar}

A experiência estética se afigura partindo da percepção do universo sensível, seja na apreciação de algum objeto artístico, na audição de uma música ou outras vivências sociais como provar uma nova gastronomia, conhecer um novo perfume ou até mesmo os fenômenos da natureza podem tornar-se um objeto estético. Para Reis (2011), a experiência estética trata-se de uma relação ao mesmo tempo social e individual entre um sujeito e um objeto, pois, na percepção estética, estão envolvidos tanto significados socialmente compartilhados quanto sentidos que remetem à singularidade do sujeito dessa experiência. Nesse sentido, as atividades desenvolvidas nas aulas de arte funcionam como um fio condutor destas experiências, portanto, a atividade de arte deve ser analisada sob uma perspectiva de educação estética.

Na perspectiva histórico-cultural do desenvolvimento humano, no contexto da educação inclusiva, Vigotski (2011) aponta que a educação estética apresenta-se como uma prática fundamental para o desenvolvimento das funções psicológicas superiores. Desta forma, o trabalho pedagógico do professor de arte apresenta-se fundamental para a inclusão, atendendo as necessidades dos alunos especiais por meio dos conteúdos e a das proposições práticas. "Um dos desafios para um projeto de ensino de arte na escola inclusiva diz respeito às representações sobre as impossibilidades e incapacidades dos alunos com deficiência de simbolizar, de realizar as operações mentais complexas e de criar" (IVONE, 2008, apud FERNANDES; 2016, p. 107).

Com relação ao deficiente intelectual, é mister levar-se em conta os esforços para se expressar, dificuldades com as abstrações e generalizações e, em alguns casos, dificuldades motoras. Nesse contexto, as experiências com o trabalho realizado na arte ressaltam os processos mentais reais, contribuindo para que o aluno possa desenvolver suas potencialidades, sendo assim, as práticas artísticas, a educação estética, realizadas para o público da educação especial necessitam de um olhar mais atento, além de ressaltar-se que o professor deve planejar suas ações, para que o aluno possa usufruir do melhor que a arte pode proporcionar.

No processo de experimentações, é vital destacar o momento da catarse, que Duarte e Fonte (2010) descrevem como um processo pelo qual o indivíduo receptor é colocado em confronto estético com a essência da realidade, por meio da superação, ainda que momentânea, da própria vida.

A catarse opera uma mudança momentânea na relação entre a consciência individual e o mundo, fazendo com que o indivíduo veja o mundo de maneira diferente daquela própria ao pragmatismo e ao imediatismo da vida cotidiana. Por meio desta momentânea suspenção da vida cotidiana, a arte exerce 
efeito formativo sobre o indivíduo, efeito esse que terá repercussões na vida do indivíduo, as quais, porém, não ocorrem de maneira direta e imediata, havendo entre elas e a catarse estética uma complexa trama de mediações que torna impossível definir a priori as consequências, para a vida de terminado indivíduo, do processo de recepção de determinada obra de arte (DUARTE; FONTE, 2010, p.152).

No trecho destacado, os autores explicitam que não se pode esperar um resultado imediato, devido à complexa trama de mediações entre a suspenção da vida cotidiana e a catarse estética. Esta consideração a respeito dos efeitos da experiência estética é um ponto relevante na avaliação do processo pedagógico e de produção artística na sala de aula, uma vez que o professor, conhecendo o aluno e o seu comportamento no desenvolvimento das atividades, identifica o momento catártico no processo, o que revela que a experiência o afetou de alguma forma, entretanto não há como mensurar o que este efeito causará a longo prazo na vida do indivíduo.

Duarte e Fonte (2010) apontam que existem aspectos na vivência estética que se assemelham à atividade educativa, isto é, para os autores "nenhuma delas transforma diretamente a sociedade, nem mesmo transforma diretamente a vida do indivíduo. Ambas, porém, podem exercer influência decisiva seja na transformação da sociedade, seja na da vida do indivíduo". Conforme Heller (apud DUARTE; FONTE; 2010, p. 155),

A arte por si só não pode humanizar a vida; porém, quando se tem a necessidade de humanizar a própria vida e dos demais também em outros níveis - [...] -, a arte proporciona um parâmetro e cumpre a função de apoio sentimental e intelectual para operar a transformação.

Ainda, acerca da proposição de Duarte e Fonte (2010), os autores advogam que existe um limite na analogia entre a experiência estética e a atividade educativa, pois a atividade educativa requer a mediação do professor para que o aluno tenha contato com o aprendizado. Neste caso, o professor faz o papel de autor, organizando os conteúdos com o objetivo de que seus alunos alcancem o conhecimento científico. Já na experiência estética, nem sempre se faz necessário o contato direto com o autor. Nesse caso, cita-se, como exemplo, ao apresentar-se uma pintura aos alunos, é correto afirmar que os educandos não estão em contato direto com o pintor, mas se relacionam com ele por meio da construção pictórica apresentada. 
Quando a pintura desperta o encantamento em um determinado aluno, cria-se uma relação entre o aluno e a produção estética, mas diferente da atividade educativa, não se exige que haja assimilação de todos os aspectos envolvidos na criação daquela obra, ou que a experiência vivenciada cause impacto imediato no aluno.

Observa-se o quão importante é a ponderação que Duarte e Fonte (2010) fazem sobre o não imediatismo dos resultados. Se o aluno não responde imediatamente à experiência, não se pode ter como fracassado o plano de aula, ainda que os objetivos não tenham sido alcançados. Cada indivíduo tem seu tempo de aprendizado e, em se tratando do deficiente intelectual, o aprendizado demanda um maior tempo de desenvolvimento, o que não pode ser impeditivo de se ofertar as mais ricas experiências e incentivo à produção artística.

\section{Notas sobre a proposta de atividade}

A proposta pedagógica aqui apresentada surgiu a partir de uma pesquisa que visa demonstrar o caráter formador da Arte. A aplicação prática foi realizada entre os meses de março, abril e maio de 2018, no período vespertino, durantes as aulas de arte em uma escola especial que presta atendimento educacional a pessoas com Síndrome de Down, localizada no município de Campo Grande/MS. A descrição e análise do processo pedagógico que se segue refere-se a um recorte de todo o trabalho que já vem sendo realizado na instituição, que possui como missão o cuidado em atender as necessidades educacionais, sociais e emocionais dos alunos.

É importante salientar que o termo recorte foi utilizado com o propósito de esclarecer que a atividade aqui apresentada foi selecionada, dentre outras, e representa uma amostra da realidade, ainda assim, a escolha não foi aleatória. Houve a preocupação com a forma como o trabalho seria apresentado dentro dos requisitos propostos para a escrita desse trabalho, que é discutir o caráter formador da arte e como isto ocorre com os alunos com Síndrome de Down, desmistificando os preconceitos a respeito das potencialidades deste grupo em especial. Para tanto, utilizou-se de pesquisa qualitativa, a partir da abordagem sócio histórica, compreendendo que o fazer pedagógico se dá por meio da inter-relação do professor e o aluno. Assim, a concepção de conhecimento e aprendizagem tem como gênese o processo social, indutor de conhecimento (FREITAS, 2002).

Além do já mencionado cuidado em selecionar a atividade, foi conveniente selecionar o grupo de alunos, com o qual os registros seriam realizados. Para o trabalho, foram selecionadas três turmas da Educação para Jovens e Adultos - EJA - $1^{\text {a }}$ etapa, que contém regularmente matriculados, no total das três turmas, 36 alunos, sendo 28 com Síndrome de Down, 7 com 
Deficiência Intelectual, 1 com Transtorno do Espectro Autista - TEA. A escolha destas turmas teve como critério o nível de desenvolvimento apresentado por cada grupo de alunos, que doravante serão mencionados como turma $\mathrm{A}$; turma $\mathrm{B}$; e turma $\mathrm{C}$.

A turma A está em processo de alfabetização, a maioria dos alunos conseguem ler e interpretar textos simples, assim como construir frases, pequenos textos e resolver questões simples de matemática. A turma B apresenta-se também está em processo de alfabetização, porém poucos alunos conseguem ler e interpretar frases completas. A turma $\mathrm{C}$ apresenta-se mista, e assim como a turma $\mathrm{B}$, poucos alunos conseguem ler e escrever. Há também alunos com comprometimento motor, dificultando o seu desenvolvimento.

Torna-se importante considerar o nível de alfabetização, uma vez que o domínio das linguagens matemática e linguística interfere na forma como os alunos portam-se diante do processo criativo, motivado pela apresentação de um repertório mais amplo do que seus colegas que ainda não desenvolveram plenamente a leitura e escrita.

Vigotski (2009, p.11) observa que os estímulos e as informações proporcionados pelo meio favorecem o desenvolvimento criativo, que ele descreve como "[...] aquela se cria algo novo. Pouco importa se o que se cria é algum objeto do mundo externo ou uma construção da mente ou do sentimento, conhecida apenas pela pessoa em que essa construção se habita e se manifesta." Neste sentido, o domínio das linguagens são agentes facilitadores do desenvolvimento, entretanto, são as experiências as quais os indivíduos são expostos que determinarão a riqueza do processo criativo. No caso das atividades de arte, tratamos das experiências estéticas e da produção cultural.

\section{Desenvolvimento das atividades}

Conforme já mencionado, a atividade foi executada junto a três turmas do EJA, no período de seis aulas, com 40 minutos cada aula, tendo como objetivos:

- Vivenciar experiências estéticas e de desenvolvimento criativo por meio da produção artística;

- Expressar nas linguagens artísticas uma atitude de busca pessoal articulando a percepção, a imaginação, a emoção, a sensibilidade, a criatividade e a reflexão ao realizar;

- Interagir com materiais, instrumentos e procedimentos variados, conhecendo-os de modo a utilizá-los nos trabalhos pessoais e/ou coletivos; 
O projeto de construção pictórica, ou como foi chamado pela professora: Pintura fora do quadro foi intitulado Partes abstratas e apresenta como inspiração o trabalho da artista plástica e arte educadora brasileira Leda Catunda. Catunda é uma famosa artista da geração dos anos 1980, que apoiou o reaparecimento da pintura em renovação às tendências conceituais dos anos 1970 . A artista busca através da pintura trazer o significado das coisas, sendo que seu foco de produção permeia o limite entre a pintura e o objeto, explorando a textura e as superfícies dos materiais industrializados, mas dando acabamento utilizando técnicas artesanais, a título de exemplo, a costura, como forma de originar uma identidade criadora.

A característica do trabalho de Leda Catunda está no limite da pintura e do objeto e promove uma gama de possibilidades de conceitos a serem trabalhados nas aulas de artes, principalmente para pessoas com deficiência intelectual, onde há uma maior necessidade de se reforçar conceitos simples como: acima/abaixo; dentro/fora. Para a aplicação desta proposta, o trabalho foi dividido em etapas, construindo um percurso que parte da instrumentalização, passando pelo processo de criação e culminando na produção artística.

No primeiro momento foi praticado o conceito de abstração da forma, estimulando os alunos a saírem do engessamento das formas geométricas, partindo para a construção de formas soltas e informais (orgânicas), explorando o uso das linhas sinuosas. Ainda nesta etapa, foram propostos exercícios por meio de desenhos em grande dimensão, visto que uma das grandes dificuldades dos alunos é lidar com grandes formatos, tanto do suporte (no caso o papel) quanto em explorar e otimizar todo o espaço disposto.

Na sequência da metodologia do trabalho, foram apresentadas as seguintes imagens das obras de Leda Catunda ao grupo de alunos:

Figura 1.

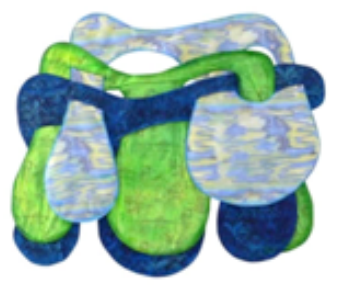

Palmeiras com Flores, 2006 , Acrílica s/ tela e plástico, $240 \times 240 \mathrm{~cm}$

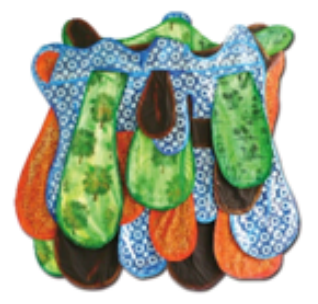

Lagos e Bananeiras II, 2007, Acrílica s/ voile e tecido, $145 \times 171 \mathrm{~cm}$

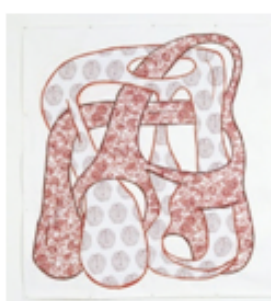

Entrelaçamento II, 2003, colagem, $223 \times 187 \mathrm{~cm}$

Fonte: Autores. 
Neste momento foi realizada a leitura da imagem, na qual os olhares foram guiados a observar as formas, as estampas, as texturas. Essa etapa foi importante para que o grupo percebesse as estratégias que a artista utilizou para montar as obras, como por exemplo, perpassar partes grandes por dentro de pequenas incisões feitas nas peças. Esta fase é chamada de instrumentalização, na qual os alunos estiveram alicerçando conceitos que foram objetivados no momento de produção, havendo aqui a mediação da professora.

A participação das pessoas mais experientes, das pessoas que elaboram/ estão elaborando conceitos organiza propositalmente, explicitamente as interações para que os jovens ou adultos (os aprendizes) elaborem conceitos. O professor (ou o adulto mais experiente) é o mediador da elaboração de conceitos da pessoa sob a sua responsabilidade (PADILHA; 2017, p.19).

A leitura mediada das produções de Leda Catunda foi um momento de construção de ideias. Destaca-se a atitude dos alunos Carlos, Marcia e José , da turma A, que já conseguiram levantar algumas hipóteses a respeito de como a Catunda organizou os elementos presentes nas obras. Estes três alunos em especial, por possuírem o pensamento mais elaborado, conseguiram traçar um raciocínio lógico, deduzindo que a artista fez cortes para entrelaçar as partes, só não conseguiram entender como foi possível uma parte grande passar por um corte pequeno. Nota-se na postura dos alunos o que Vigotski (2009) chama de atividade combinatória ou criadora, daí a relevância de ampliar o repertório ofertando as mais variadas referencias e experiências.

Toda a atividade do homem que tem como resultado a criação de novas imagens ou ações, e não só reprodução de impressões ou ações anteriores a sua experiência, pertence a esse segundo gênero de comportamento criador ou combinatório. $O$ cérebro não é apenas um órgão que conserva e reproduz a nossa experiência anterior, mas também o que combina e reelabora, de forma criadora, elementos da experiência anterior, erigindo novas situações e novos comportamento (VIGOTSKI; 2009, p.13).

\footnotetext{
${ }^{1}$ Aqui são apresentados nomes fictícios, a fim de preservar a identidade dos alunos.
} 
Dos alunos das demais turmas, somente Roberta, da turma B, traçou hipóteses e arriscou dar algum sentido para as imagens, que mesmo sendo abstrata, a aluna insistia que deveria estar representando alguma coisa, o que demonstra uma dificuldade com a abstração, pois eles tendem a buscar um significado concreto, atrelado aos conceitos cotidianos. Neste momento, a instrumentalização e a mediação são necessárias para a transformação destes conceitos cotidianos em conceitos científicos (PADILHA, 2017). No caso de Roberta, foi importante apresentar e reforçar o entendimento dos elementos visuais que estão presentes na imagem, como cor, contraste, forma, textura, etc. Para a pessoa sem deficiência, estes elementos se apresentam de forma clara, já para o deficiente intelectual, há um esforço maior para compreender as relações entre os elementos visuais, como entre as cores e as texturas visuais (estampas), por exemplo.

Dando prosseguimento, iniciou-se a etapa da produção artística, que também se fez valer com mediação da professora. Aos alunos foram dispostos canetões para cartaz e folhas de papel pardo, nas dimensões de $60 \times 70 \mathrm{~cm}$. A proposta era de que cada um desenhasse uma forma orgânica, que ocupasse todo o espaço do papel e pintasse o desenho com diferentes cores e texturas visuais. Nesta etapa da atividade, os alunos foram autônomos, visto que era um procedimento simples e de livre expressão. Embora algum aluno apresentasse dificuldade motora em manusear o canetão, e mesmo havendo a necessidade do auxílio, mediação do professor ou de outros colegas, a produção foi de sua autoria.

Ainda nesta etapa, já foi introduzido um outro desafio: recortar os desenhos, criando grandes peças de um "quebra-cabeça”. O recorte das figuras é citado aqui como desafio, visto que, apesar da idade, muitos alunos apresentam necessidades de desenvolver a coordenação motora fina, havendo dificuldades em manusear uma tesoura, no sentido de cortar sobre a linha traçada e fazer recortes sinuosos. Por vezes erram a curva do desenho, fazendo um corte reto. Outra parte do desafio do recorte está na dimensão do papel, que é relativamente grande - tornando a ação desajeitada, os alunos deveriam elaborar estratégias ao realizar o corte contínuo. O que parece ser uma ação simples, para a pessoa com Síndrome de Down é um desafio a ser superado. Segundo Anache (2012), este momento é fundamental a fim de observar a Zona de Desenvolvimento Proximal do aluno.

Para observar como esta "zona" se comporta, é preciso considerar três características básicas: 1) propor ao estudante situações desafiadoras, sem que sejam extremamente difíceis; 2) dirigir o aluno, através de pistas, para que possa cumprir o objetivo proposto pela tarefa; 3) avaliar o processo de autonomização da criança no desempenho da tarefa proposta (ANACHE, 2012, p.231). 
Com a ajuda da professora, oferecendo estímulos e exercícios de coordenação motora, aos poucos, dentro do seu tempo, cada aluno foi compreendendo como conduzir a tarefa e, em alguns casos, quando conquistada a habilidade, eles auxiliavam os colegas neste processo.

Concluída a etapa de produção das peças do "quebra-cabeça", seguiu-se a segunda etapa do trabalho: unir as peças para criar uma forma única, que contou com a ajuda do professor para fazer as incisões, quando necessário, utilizando um estilete, uma vez que não é seguro para os alunos manipularem esta ferramenta. Este momento foi muito importante, pois permitiu que os alunos expusessem as ideias para o grupo, verbalizando e objetivando o que foi mentalmente criado. A socialização das ideias foi um ponto importante do processo, promovendo o movimento dialético de aprendizagem. A arte está, permanentemente, ligada à vida e às relações sociais e na forma como é trabalhado a realidade e a produção cultural, cristalizas as complexas atividades mentais, as quais podem ser apropriadas pelos demais seres humanos (BARROCO; SUPERTI, 2014).

A peça criada pela turma $\mathrm{A}$ foi a que proporcionou maiores discussões, gerando até conflito entre dois alunos. $\mathrm{O}$ aluno Carlos elaborou uma proposta de montagem de fato interessante, porém a aluna Márcia também propôs uma forma diferente de organização. Ambos os alunos possuíam argumentos plausíveis; a proposição de Carlos se referia à combinação de cores, um contraste entre a peça roxa com a parte amarela, já a proposta de Márcia se referia à forma. A ideia era fazer algumas incisões na peça amarela e passar partes da peça verde por dentro dos cortes; neste momento a aluna demonstrou um pensamento lógico. Quanto aos demais alunos do grupo, todos permaneciam passivos, apenas concordando com as ideias propostas, um ou outro colega arriscava alguma organização diferente, mas sem muito êxito, no sentido de objetivar no trabalho o que foi mentalmente criado. A postura passiva dos colegas não suprime a importância da vivência artística e da socialização das ideias, ainda que estas sejam menos elaboradas.

Com relação à turma $\mathrm{C}$, o processo de criação foi diferenciado, considerando o as necessidades educacionais apresentadas pela maioria dos alunos, havendo poucas trocas de ideias. Foram necessárias mais intervenções da professora, assim como adaptação de materiais: utilizar um engrossador no cabo do pincel para que Fabio pudesse pintar o desenho; auxiliar alguns alunos quanto à utilização da tesoura. Quando necessário, eram propostos alguns exercícios de recorte de papeis.

A culminância do projeto se deu por meio da apresentação dos trabalhos para a apreciação da comunidade escolar, cuja organização foi realizada pelos próprios alunos, sob a orientação da professora. As produções foram expostas em uma parede do refeitório e em quatros painéis moveis, ficando à disposição do público por uma semana. 
Foi oportuna a participação dos alunos na montagem da exposição, pois se verificou o momento de consolidação do trabalho, agindo positivamente na autoestima e na formação de consciência, ou seja, uma atividade psíquica propriamente humana, formada a partir da ação do homem sobre o mundo (BARROCO E SUPERTI, 2014). A participação na exposição foi uma ação que gerou nos alunos o sentimento de pertencimento social, tanto por participar do processo de montagem, quanto por compartilhar socialmente suas produções artísticas. Complementando a fala das autoras, Duarte e Fontes (2010) citam que a arte possibilita o relacionamento dos indivíduos com seus sentimentos, como um objeto externo, interiorizado por meio da catarse.

No que se refere à postura do fruidor diante da produção cultural, destaca-se o caso de Daniel, aluno com transtorno do Espectro Autista - TEA, da turma A, muito sensível para as questões que envolvem a arte, apresentando uma habilidade artística acima da média. $\mathrm{O}$ aluno não participou do processo de criação, pois ele realiza atividades extracurriculares em outro setor da instituição, participando somente da montagem da exposição.

Daniel ficou estático diante à mesa em que as peças estavam postas, e na posição de fruidor, esboçou uma expressão de encantamento ao ter contato com as peças produzidas pelos colegas.

\author{
Prof: : - Que cara é essa? \\ Daniel: - Olha, é arte! É muito linda! \\ Prof.: - Então, você gostou dos trabalhos? \\ Daniel: - Sim, eu gosto de arte. Gosto de fazer arte)
}

Daniel tomou frente da organização, propondo como as peças deveriam ser fixadas na parede. Uma vez que as peças eram abstratas e não havia uma posição preestabelecida, cabia ao grupo decidir qual seria a maneira mais interessante de apresentação. $\mathrm{O}$ caso deste aluno ilustra a já mencionada proposição de Duarte e Fontes (2010), a respeito da catarse estética e como não se pode mensurar o seu efeito no psiquismo humano. No caso de Daniel a resposta foi imediata, e este encantamento suscitou nos colegas/ autores a tomada de consciência por meio do sentimento de aprovação.

Todo o desenvolvimento da atividade artística foi permeado por uma metodologia de avaliação cuja natureza é essencialmente qualitativa. Esta abordagem prioriza as relações e contextualização que o aluno consegue formar do conteúdo proposto em aula, com sua realidade social-histórica. 
Contribuir para uma aprendizagem mais efetiva implica, em primeiro lugar, refletir sobre que tipo de aprendizagem se pretende, assim como questionar o lugar dominante que ocupa suas formas mais simples e reprodutivas no contexto escolar. O que pretendemos como professores? O que esperamos que o aluno aprenda? O que valorizamos positivamente de sua ação? Quais são os resultados que nos deixam satisfeitos? O que nos defrauda? A representação da aprendizagem como produção e não como reprodução é essencial para poder delinear estratégias pedagógicas que contribuam para formas de aprendizagem compreensivas e criativas (MARTINEZ; REY, 2017, p. 143).

Pode-se perceber ao longo da narrativa que a avaliação ocorreu em todas as etapas da produção artística. Em se tratando do ensino de arte na educação especial, é relevante o professor ter a avaliação alicerçada nas experiências, portanto, deve-se prezar todas as etapas do processo de desenvolvimento da atividade, considerando as subjetividades, que Anache (2012) descreve com a constituição de sistemas simbólicos e de sentido subjetivo, integrando os aspectos constitutivos da personalidade. A autora diz ainda que "o sujeito expressa a sua capacidade nas relações concretas da vida, portanto carregada de sentidos, necessários para manter o curso do seu desenvolvimento" (ANACHE, 2012, p. 234).

Conforme o exposto, o delineamento da subjetividade por todo o processo enfatiza a importância de considerar cada etapa do trabalho, percebendo, ao fim, que a produção não só modificou o aluno/autor, como também os sujeitos fruidores da obra. Torna-se mais frutífero quando se considera as manifestações psicológicas que o aluno apresenta no processo. Estas manifestações estarão, de certa forma, presentes no produto, portanto, quando a avaliação é realizada somente ao final do processo, os resultados tornam-se inconsistentes.

Não é condenável o professor de arte submeter sua avaliação às análises mais rígidas, em que leva em conta somente questões objetivas como movimento de pinça, coordenação motora, seleção e agrupamento de cores e formas, entre outros. Entretanto, ao fazer a análise de maneira hermética, o professor ignora o que há de mais importante e bonito no trabalho de arte: as relações criadas na experiência estética e a produção cultural dos alunos.

\section{Considerações finais}

A proposta de uma produção artística apresentada neste artigo evidenciou que as atividades de arte voltada para a educação especial, neste caso, para pessoas com Síndrome de Down, não são meramente "um fazer por fazer", ou passatempo. Também não objetiva meramente propiciar 
exercícios técnicos para aperfeiçoamento de habilidades motoras, por exemplo, os quais, por mais que estes exercícios permeiem o processo, não é necessariamente o fim último. Do contrário, essa produção tem caráter pedagógico e é carregada de sentido.

A narrativa salienta que, ainda que pareça lúdico, a produção artística deve ser tomada com seriedade e zelo no processo avaliativo, pois cada detalhe do desenvolvimento da atividade é carregado de sentido, tanto subjetivos quanto objetivos, que afetam todos os atores envolvidos.

\begin{abstract}
A produção artística é uma necessidade social que envolve o aspecto do fazer, da elaboração estética, do produzir atividades com base no conhecimento dos elementos das linguagens e das suas formas expressivas. Não pode ser restrita a um fazer técnico, estereotipado ou padronizado, mais sim contribuir para que a criança elabore continuamente nas suas possibilidades expressivas e criadoras e aprimore a compreensão estética (CASTILHO; NASCIMENTO; FERNANDES; 2018, p.162).
\end{abstract}

Considera-se importante a plena consciência do caráter formador da arte, para que se possa elaborar atividades cada vez mais ricas, possibilitando ao aluno manifestar-se criativamente, desenvolvendo o seu potencial. No que tange à educação especial, este entendimento é fundamental, para que não ocorram indiligências no processo de ensino e de aprendizagem. Finalmente, é fundamental esclarecer que trabalhar com a diversidade de sujeitos implica compreender o tempo de aprendizagem do aluno e os significados que ele dá ao processo de construção do conhecimento.

\title{
REFERÊNCIAS
}

ANACHE, Alexandra Anache. Dimensões subjetivas envolvidas na avaliação da aprendizagem de pessoas com deficiência intelectual. In: MARTINÉZ, Albertina Mitijáns; SCOZ, Beatriz Judith Lima; CASTANHO, Marisa Irene Siqueira. Ensino e aprendizagem: a subjetividade em foco. Brasília: Liber Livros, 2012.

BARROCO, S.M.S; SUPERTI, T. Vigotski e o estudo da psicologia da arte: contribuições para o desenvolvimento humano. Psicologia e Sociedade. Belo Horizonte, v. 26, n. 1, p. 22-31, 2014.

CAMPO GRANDE, Secretaria de Estado de Educação. Referencial Curricular da Rede Estadual de Ensino do Estado de Mato Grosso do Sul. Ensino Fundamental. Governo do Estado de Mato Grosso do Sul, 2012. 
CASTILHO, Ana Lucia Serrot; NASCIMENTO, Sidnei Camargo do; FERNANDES, Vera Lúcia Penzo; in Secretaria Municipal de Educação. Referencial Curricular da Rede Municipal de Ensino $1^{\circ}$ e $2^{\circ}$ do Fundamental. Prefeitura do Município de Campo Grande/MS, p.153 -176. 2008.

DUARTE, Newton; F ONTE, Sandra Soares Della. Arte, conhecimento e paixão na formação humana: sete ensaios de Pedagogia histórico-crítica. Campinas/SP: Editora Autores Associados, 2010.

FERNANDES, Vera Lúcia Penzo. A Criatividade no ensino das artes visuais: da reprodução à inclusão. $1^{\mathrm{a}}$ ed. Curitiba: Editora Appris, 2016.

FREITAS, Maria Teresa de Assunção. A abordagem sócio histórica como orientadora da pesquisa qualitativa. Sielo 2002 disponível em http://www.scielo.br/scielo.php?script=sci_arttext\&pid= S0100-15742002000200002 Acesso em: 02julho2018.

MARTÍNEZ, Albertina Mitjáns; REY, Fernando Gonzáles. Psicologia, Educação e Aprendizagem Escolar: avançando na contribuição da leitura cultural-histórica. São Paulo: Cortez Editora, 2017.

PADILHA, Anna Maria Lunardi. Desenvolvimento Psíquico e Elaboração Conceitual por Alunos com Deficiência Intelectual na Educação Escolar. Revista Brasileira de Educação Especial, Marília, v. 23, n. 1, p. 9-20, 2017.

REIS, Alice Casanova. A experiência estética sob um olhar fenomenológico. Arquivos Brasileiros de Psicologia, 2011, Disponível em http://seer.psicologia.ufrj.br/index.php/abp/article/ view/693/493 Acesso em: 19maio 2018.

VIGOTSKI, L S. A Construção do Pensamento e da Linguagem. São Paulo: Editora Martins Fontes, 2001.

A defectologia e o estudo do desenvolvimento e da educação da criança anormal. Educação e Pesquisa. vol.37 no.4 São Paulo Dec. 2011.

Imaginação e criação na infância: ensaios pedagógicos; apresentação e comentários: Ana

Luiza Smolka; tradução Zóia Prestes. São Paulo: Editora Ática, 2009.

Psicologia da Arte. São Paulo: Martins Fontes, 1999. 


\section{ANEXOS}

Figuras 1 e 2: Alunos produzindo
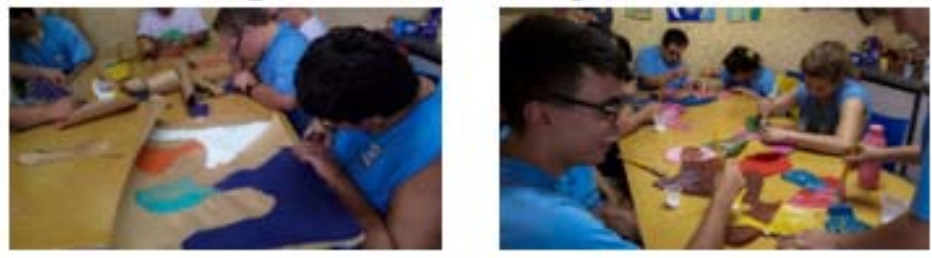

Figuras 3 Alunos montando exposição

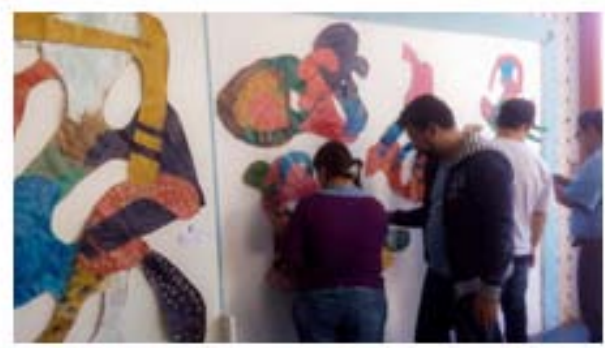

Figuras 4, 5 e 6: Produções
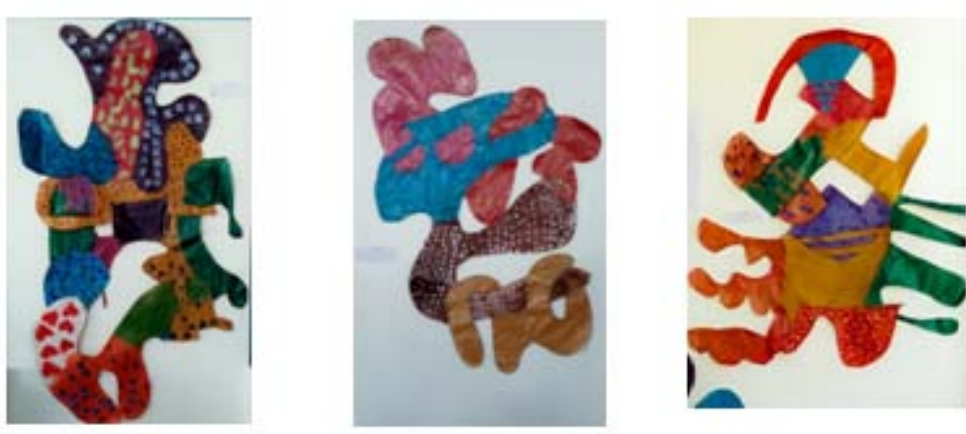

Fonte: Acervo das autoras, 2018. 